\title{
Correction to: Self-management Behaviors and Anthropometric Indices after Roux-en-Y Gastric Bypass
}

\author{
Zahra Sobhani ${ }^{1} \cdot$ Masood Amini $^{2} \cdot$ Maryam Zarnaghash $^{3} \cdot$ Hamid Reza Foroutan $^{2}$. \\ Seyed Vahid Mojab ${ }^{4} \cdot$ Hajar Khazraei $^{1} \cdot$ Seyed Vahid Hosseini ${ }^{1}$
}

Published online: 19 March 2021

(C) Société Internationale de Chirurgie 2021

\section{Correction to: World J Surg https://doi.org/10.1007/s00268-021- 05959-y}

The author affiliations are correct as reflected here. The original article has been corrected.

Publisher's Note Springer Nature remains neutral with regard to jurisdictional claims in published maps and institutional affiliations.

The original article can be found online at https://doi.org/10.1007/ s00268-021-05959-y.

Seyed Vahid Hosseini

colorectal2@sums.ac.ir

1 Colorectal Research Center, Shiraz University of Medical Sciences, Shiraz, Iran

2 Laparoscopy Research Center, Shiraz University of Medical Sciences, Shiraz, Iran

3 Psychology Department, Psychology and Educational Sciences Faculty, Islamic Azad University, Marvdasht Branch, Marvdasht, Iran

4 Department of Cardiovascular, School of Medicine, Shiraz University of Medical Sciences, Shiraz, Iran 